\title{
A matrix metalloproteinase inhibitor enhances anti-cytotoxic $T$ lymphocyte antigen- 4 antibody immunotherapy in breast cancer by reprogramming the tumor microenvironment
}

\author{
MINGYUE LI, SHUGANG XING, HAIYING ZHANG, SIQI SHANG, XIANGXIANG LI, \\ BO REN, GAIYUN LI, XIAONA CHANG, YILEI LI and WEI LI \\ The Key Laboratory of Pathobiology, Ministry of Education, The College of Basic Medical Sciences, \\ Jilin University, Changchun, Jilin 130021, P.R. China
}

Received October 13, 2015; Accepted November 23, 2015

DOI: 10.3892/or.2016.4547

\begin{abstract}
Anti-cytotoxic T lymphocyte antigen-4 (CTLA-4) treatment is effective for the treatment of primary tumors, but not sufficient for the treatment of metastatic tumors, likely owing to the effects of the tumor microenvironment. In this study, we aimed to determine the therapeutic effects of combined treatment with a matrix metalloproteinase (MMP) inhibitor (MMPI) and anti-CTLA-4 antibody in a breast cancer model in mice. Interestingly, combined treatment with MMPI and antiCTLA-4 antibody delayed tumor growth and reduced lung and liver metastases compared with anti-CTLA-4 alone or vehicle treatment. The functions of the liver and kidney in mice in the different groups did not differ significantly compared with that in normal mice. The $\mathrm{CD} 8^{+} / \mathrm{CD} 4^{+}$ratio in $\mathrm{T}$ cells in the spleen and tumor were increased after monotherapy or combined anti-CTLA-4 antibody plus MMPI therapy compared with that in vehicle-treated mice. Anti-CTLA-4 antibody plus MMPI therapy reduced the percentage of regulatory T cells (Tregs) and myeloid-derived suppressor cells (MDSCs) and decreased the Treg/Th17 cell ratio in the spleen compared with those in the vehicle-treated group. Additionally, anti-CTLA-4 antibody plus MMPI therapy reduced the percentages of regulatory $\mathrm{T}$ cells (Tregs), myeloid-derived suppressor cells (MDSCs),
\end{abstract}

Correspondence to: Professor Wei Li, The Key Laboratory of Pathobiology, Ministry of Education, The College of Basic Medical Sciences, Jilin University, Changchun, Jilin 130021, P.R. China E-mail: liwei2006@jlu.edu.cn

Abbreviations: MMP, matrix metalloproteinase; MMPI, matrix metalloproteinase inhibitor; CTLA-4, cytotoxic $\mathrm{T}$ lymphocyte antigen-4; TME, tumor microenvironment; Tregs, regulatory T cells; MDSCs, myeloid-derived suppressor cells; MVD, microvessel density; ALT, alanine aminotransferase; AST, aspartate aminotransferase; IL, interleukin; BSA, bovine serum albumin; VEGF, vascular endothelial growth factor; TGF, transforming growth factor; STAT3, signal transducer and activator of transcription; PGE2, prostaglandin E2

Key words: matrix metalloproteinase, cytotoxic $\mathrm{T}$ lymphocyte antigen- 4 blockade, tumor microenvironment, breast cancer, vessel and Th17 cells in tumors compared with that in the vehicletreated group. Moreover, combined treatment with MMPI and anti-CTLA-4 antibody reduced the microvessel density (MVD) in tumors compared with that in vehicle or MMPItreated mice. There was a negative correlation between MVD and the $\mathrm{CD}^{+} \mathrm{T}$ cell percentage, $\mathrm{CD}^{+} \mathrm{T}$ cell percentage, and $\mathrm{CD}^{+} / \mathrm{CD}^{+} \mathrm{T}$ cell ratio, but a positive correlation with Tregs, Th17 cells, Treg/Th17 cell ratio, and MDSCs. Thus, these data demonstrated that addition of MMPI enhanced the effects of anti-CTLA-4 antibody treatment in a mouse model of breast cancer by delaying tumor growth and reducing metastases.

\section{Introduction}

Cytotoxic T lymphocyte antigen-4 (CTLA-4) is an inhibitory molecule found on $\mathrm{T}$ cells. Immunotherapy by blocking CTLA-4 can enhance T-cell activation and proliferation and improve antitumor immune responses (1). However, antiCTLA-4 antibody therapy is not sufficient for the treatment of metastatic malignant tumors (2), likely owing to the effects of the tumor microenvironment (TME) (3). The TME has a more stable genetic background and has been shown to participate in regulating tumor immune escape and mediating the sensitivity of tumor cells to anticancer drugs (4-7). Matrix metalloproteinases (MMPs) are the primary factor regulating the TME through degradation of the extracellular matrix and promotion of tumor angiogenesis (8). Moreover, MMPs play a key role in promoting the occurrence and development of cancer (9). However, the specific effects of combined inhibition of CTLA-4 and MMPs in breast cancer are unknown.

Therefore, in this study, we constructed a breast cancer model in mice using a highly metastatic breast cancer cell line. We used this model to evaluate the therapeutic effects of anti-CTLA-4 antibody therapy alone or combination with an MMP inhibitor (MMPI) and to explore the role of the TME in tumor treatment.

\section{Materials and methods}

Murine mammary carcinoma cells and the animal model. The 4T1 murine mammary carcinoma cell line harboring the lucif- 
erase construct was provided by the Pathology Department of the College of Basic Medical Sciences, Jilin University, China. 4T1 cells were cultured in RPMI-1640 medium (Gibco, USA) supplemented with $10 \%$ fetal bovine serum (FBS; Hyclone, USA) and incubated at $37^{\circ} \mathrm{C}$ in an atmosphere containing $5 \% \mathrm{CO}_{2}$. In the logarithmic growth phase, 4T1 cells were collected and diluted to a concentration of $5 \times 10^{6}$ cells $/ \mathrm{ml}$ with phosphate-buffered saline (PBS). Next, $0.2 \mathrm{ml}$ of the cell suspension was injected subcutaneously into the right flanks of 6-8-week-old female BALB/c mice, provided by the Laboratory Animal Center of the College of Basic Medical Sciences, Jilin University. All procedures followed the animal care regulations of the University Health Network and were approved by the Research Ethic Board of Jilin University.

Treatment of tumor-bearing mice. Tumor nodules reached $50 \mathrm{~mm}^{3}$ on day 3 . Mice were randomly divided into four groups as follows: vehicle, anti-CTLA-4 antibody alone (a-CTLA-4); MMPI alone, and combination therapy (a-CTLA-4 plus MMPI). Mice were treated with $100 \mu \mathrm{g}$ anti-CTLA-4 antibody (clone, 9H10; BioXCell, West Lebanon, NH, USA) by intraperitoneal (i.p.) injection once every two day and/or with $0.1 \mathrm{MMPI}(1 \mathrm{mg} / \mathrm{kg})$ by subcutaneous injection once every two days. The MMPI potassium ferricyanide $\left\{\mathrm{K}_{3}\left[\mathrm{Fe}(\mathrm{CN})_{6}\right]\right\}$ $(10,11)$, was kindly provided by Professor Xuexun Fang (Key Laboratory for Molecular Enzymology and Engineering of Ministry of Education, Jilin University, China). Mice in the vehicle group were treated with an equal volume of normal saline and PBS. The dosages used in the combined treatment group were equal to those used in the monotherapy groups. The longest (a) and shortest (b) diameters of the tumor were measured with calipers every 3 days, and tumor volume was estimated by the formula $\mathrm{V}=\mathrm{ab}^{2} / 2$. On days 7,21 and 35 , tumors were measured using an Ultrasound Biomicroscopy InviVue instrument (PanoView $\beta 1500$; Taiwan).

Biophotonic imaging of animals. Mice were anesthetized by i.p. injection of $4 \%$ chloral hydrate and then subjected to i.p. injection with $200 \mu \mathrm{l}$ D-luciferin $(15 \mathrm{mg} / \mathrm{ml}$; GoldBio, St. Louis, MO, USA). After $10 \mathrm{~min}$, the mice were imaged using a small animal in vivo optical imaging system (IVIS Spectrum; Caliper Life Sciences, USA).

Hematoxylin and eosin $(H \& E)$ staining. Mice were sacrificed. The lungs and livers were immediately placed in Bouin's fixation and $10 \%$ formaldehyde. After $48 \mathrm{~h}$, metastatic lesions on the surface of the lungs (faint yellow in color) were counted without the use of a microscope. The lungs and livers of each mouse were then embedded in paraffin, sectioned, stained with H\&E staining, and examined histologically for evidence of metastatic lesions within the lung and liver tissue. For each lung and liver, three consecutive sections, separated by $200 \mu \mathrm{m}$, were collected. The sections was randomized and coded, and the total number of metastatic foci was counted.

Functional tests for the liver and kidneys. Peripheral blood was obtained from each mouse and centrifuged at $500 \mathrm{x} \mathrm{g}$ for $20 \mathrm{~min}$ after standing at room temperature for $20 \mathrm{~min}$. The supernatant was collected as serum. Total protein, serum albumin, serum globulin, albumin/globulin, alanine amino- transferase (ALT), aspartate aminotransferase (AST), ALT/ AST, alkaline phosphatase, urea, creatinine, and uric acid in serum were measured using an automatic biochemical analyzer (Beckman Coulter, USA).

Flow cytometry analysis. The spleens of mice were placed in cold RPMI-1640 medium immediately and then cut into small pieces with eye scissors. Single-cell suspensions of spleen tissues were acquired after filtration with 300- and 100-mesh filters. Single-cell suspensions of bone marrow tissues were obtained from the thigh bones of mice after being washed with cold PBS. The red blood cells were then disrupted within the cell suspension. For treatment, $2 \times 10^{6}$ cells were stimulated with phorbol 12-myristate 13-acetate (PMA; Sigma, St. Louis, MO, USA; $50 \mathrm{ng} / \mathrm{ml}$ ) plus $2 \mu \mathrm{g} / \mathrm{ml}$ ionomycin (Sigma) and monensin (Sigma; $5 \mu \mathrm{g} / \mathrm{ml}$ ) for $5 \mathrm{~h}$. The cells were then collected for Th17 cytokine staining. Subsequently, they were fixed and/or permeabilized using fixation/permeabilization kits (BD, USA) according to the manufacturer's instructions, and incubated with anti-interleukin (IL)-17A-Alexa Fluor (BD), anti-CD4-PE (BD), anti-CD4-APC (BD), anti-CD25-PE-CyTM7 (BD), anti-FoxP3-PE (eBioscience, San Diego, CA, USA), anti-CD3e-FITC (BD), anti-CD4-PE$\mathrm{CyTM}^{7}$ (BD), anti-CD8-PE (BD), anti-CD11b-APC (BD), and anti-Gr-1-PE (BD) antibodies for $40 \mathrm{~min}$ at $4^{\circ} \mathrm{C}$. The cells were incubated with rat anti-mouse CD16/CD32 (BD) for $30 \mathrm{~min}$ before $\mathrm{CD} 1 \mathrm{~b}$ and $\mathrm{Gr}-1$ staining at $4^{\circ} \mathrm{C}$. Flow cytometry (BD) was performed, and data were analyzed using FlowJo software.

Immunohistochemistry analysis. For immunohistochemical analysis of microvessel density (MVD), 2- $\mu$ m-thick sections of formalin-fixed, paraffin-embedded mammary tumor tissue sections were deparaffinized in xylene and rehydrated in graded alcohols. For antigen retrieval, slides were immersed and boiled for $5 \mathrm{~min}$ in citrate buffer ( $\mathrm{pH}$ 6.0). Slides were incubated with a peroxidase inhibitor and horse serum blocking solution for $30 \mathrm{~min}$ and then subjected to overnight staining with rat anti-mouse CD34 primary monoclonal antibodies (1:100 dilution; ab81289; Abcam, USA) at $4^{\circ} \mathrm{C}$. Slides were then washed three times with PBS-T, incubated with horse anti-rat secondary antibodies for $30 \mathrm{~min}$ at room temperature, washed again with PBS-T three times, and incubated in DAB peroxide substrate solution. Counterstaining was performed with Harris hematoxylin counterstain. MVD was determined as the mean number of microvessels under five microscopic fields (200x).

Immunofluorescence analysis. Immunofluorescence staining of slides was performed as described for immunohistochemistry until antigen retrieval. Then, slides were treated with or without $1 \%$ Triton X-100 for $20 \mathrm{~min}$, followed by blocking with $5 \%$ bovine serum albumin (BSA) for $1 \mathrm{~h}$ at room temperature. Subsequently, slides were incubated with anti-CD3e-FITC (BD), anti-CD8a-PE (BD), anti-CD4-PE(BD), anti-CD11b-FITC(BD), anti-Gr-1-PE(BD), anti-Foxp3-PE (BD), and anti-IL-17A-Alexa Fluor 647 (BD) for $30 \mathrm{~min}$ at room temperature. Slides were then washed three times with PBS-T, incubated with Hoechst-33342 for 5 min at room temperature, washed again with PBS-T three times, and sealed with glycerin. 


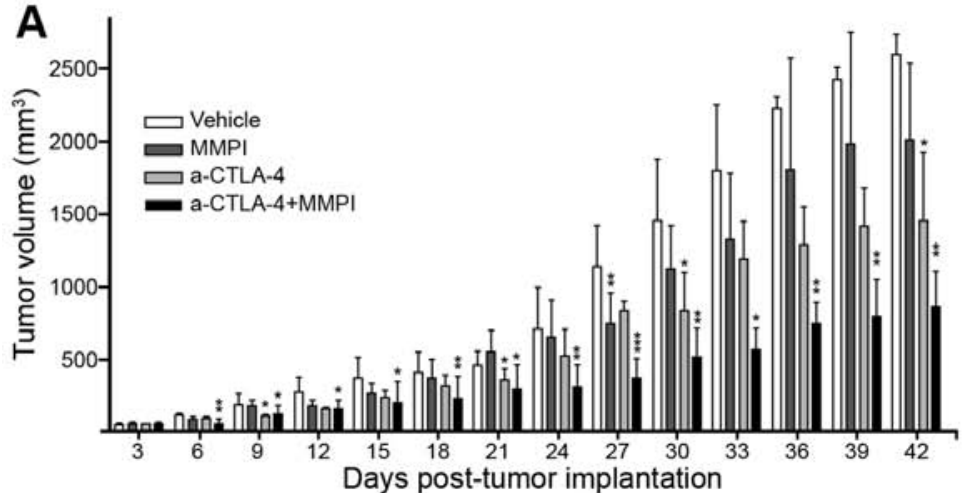

B
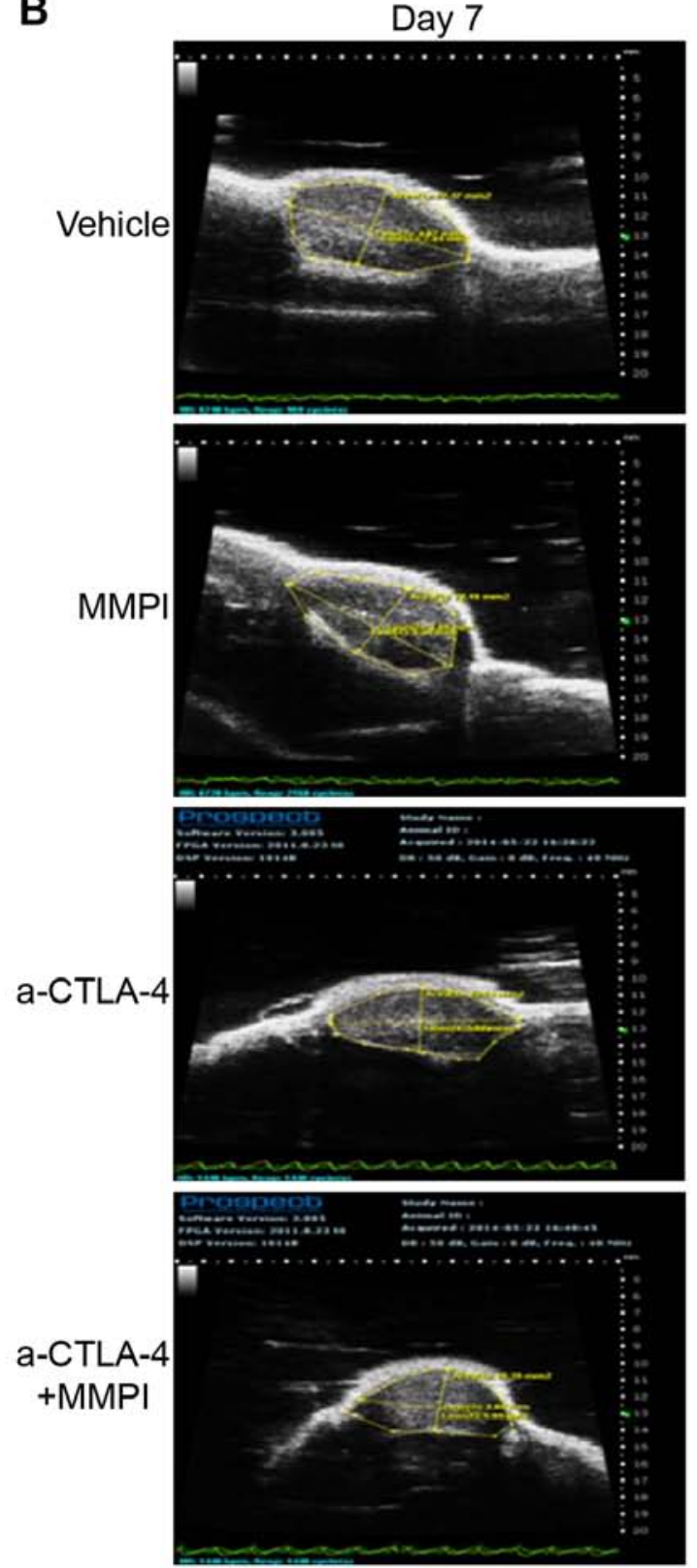

C

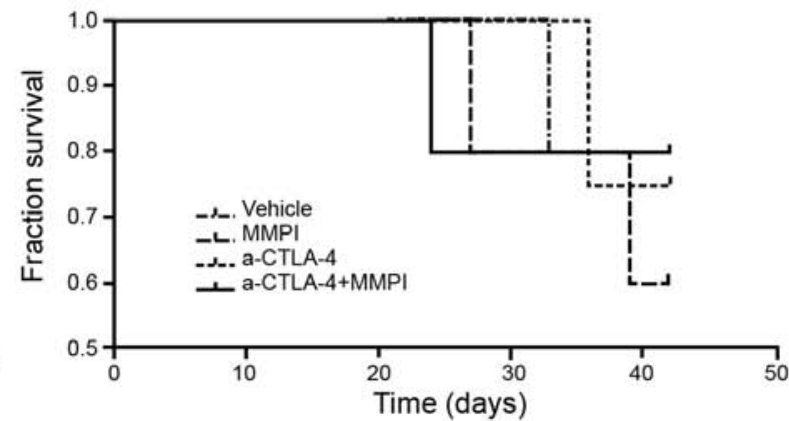

Day 21


Figure 1. Effects of an MMP inhibitor and anti-CTLA-4 antibody treatment on breast cancer growth. Vehicle (saline and PBS), MMPI + a-CTLA-4 (1 mg/kg potassium ferricyanide and $100 \mu \mathrm{g}$ anti-CTLA-4 antibody), and MMPI (1 mg/kg potassium ferricyanide) groups included five mice each, whereas the a-CTLA-4 group (100 $\mu \mathrm{g}$ anti-CTLA-4 antibody) included three mice. Treatment was started on day 3 after subcutaneous inoculation of $4 \mathrm{~T} 1 \mathrm{cells}$ into the right flanks of 6-8-week-old female BALB/c mice until day 42. (A) The growth of breast cancer. The longest diameter (a) and shortest diameter (b) were measured using calipers every 3 days and tumor volume was estimated by the formula $\mathrm{V}=\mathrm{ab}^{2} / 2$. The mean tumor volume was determined for each group of mice. Asterisks $(*)$ show comparisons with the vehicle control (Student's t-tests, non-parametric tests). ${ }^{*} \mathrm{P}<0.05 ;{ }^{* *} \mathrm{P}<0.01 ;{ }^{* * *} \mathrm{P}<0.001$. The mean tumor volume between $\mathrm{MMPI}$ + a-CTLA-4 and vehicle group was statistically significant $(\mathrm{P}<0.05$, Student's t-tests) according to analysis of the total days. (B) Breast cancer growth was measured by ultrasound. The tumor area was measured along the longitudinal axis of the tumor by ultrasound on days 7, 21 and 35 after injection of $4 \mathrm{~T} 1$ cells. (C) Survival rates in tumor-bearing mice (Kaplan-Meier analysis). 
Statistical analysis. All values were expressed as means \pm standard deviations (SDs). All statistical analyses were performed using Student's t-tests, non-parametric tests, or Spearman correlation analyses. Differences or correlations with P-values of $\leq 0.05$ were considered significant.

\section{Results}

Addition of the MMPI enhances the inhibitory effects of the anti-CTLA-4 antibody on breast cancer growth. First, we established a breast cancer model by subcutaneous inoculation of $4 \mathrm{~T} 1$ cells in order to easily monitor tumor growth using ultrasound and calipers. By day 3, tumor nodules reached $\sim 50 \mathrm{~mm}^{3}$; therefore, treatments, including anti-CTLA-4 antibody and MMPI, were applied beginning on day 3. Our results demonstrated that treatment with the MMPI or MMPI plus anti-CTLA-4 antibody inhibited the growth of transplanted tumors compared with vehicle or anti-CTLA-4 antibody alone to varying degrees. Indeed, according to analysis of the total days, combined treatment caused a significant reduction in the growth of breast tumors compared with that in vehicle-treated mice $(\mathrm{P}<0.05$; Fig. 1A). Additionally, ultrasonography on days 7, 21 and 35 revealed that tumors in mice treated with anti-CTLA-4 antibody and MMPI were significantly smaller than those in mice treated with vehicle, MMPI alone, or anti-CTLA-4 antibody alone (Fig. 1B). However, the combination treatment had no effect on the survival of tumor-bearing mice ( $\mathrm{P}>0.05$; Fig. 1C).

Treatment with the MMPI enhances the effects of the antiCTLA-4 antibody on breast cancer metastasis. In order to visualize tumor metastasis in live mice, we constructed a mouse model of breast cancer using 4T1 cells stably expressing luciferase. D-luciferin was applied on day 42 for detection of tumor metastasis using a small animal in vivo optical imaging system. The results showed that the mice in the vehicle group had metastatic lesions, whereas the mice in the other groups had no metastatic lesions (Fig. 2A).

Observation of fixed lungs showed that the number of tumor metastases on the lung surface was significantly reduced after combined treatment $(\mathrm{P}<0.05$; Fig. $2 \mathrm{~B})$. However, there was no significant reduction after treatment with anti-CTLA-4 antibody alone or MMPI alone ( $\mathrm{P}>0.05$; Fig. 2B). Additionally, analysis of paraffin-embedded lung and liver sections stained with $\mathrm{H} \& \mathrm{E}$ revealed that both tissues had reduced numbers of metastases after the combined treatment $(\mathrm{P}<0.001$; Fig. $2 \mathrm{C})$. However, there was no significant difference in the number of metastases between the anti-CTLA-4 antibody group and vehicle group (Fig. 2C).

Effects of the MMPI and anti-CTLA-4 antibody on the function of the liver and kidney. MMPIs have been reported to have toxic effects. Therefore, in this study, we examined changes in liver and kidney function in mice after treatment with the MMPI. The results showed that the liver and kidney functions of tumor-bearing mice treated with the MMPI did not differ from those of control mice ( $\mathrm{P}>0.05$; Fig. 3 ), indicating that the MMPI used in this study did not damage the liver or kidneys of mice.
Treatment with the MMPI and anti-CTLA-4 antibody improves the immune microenvironment in mice. Our data showed that MMPI could enhance the therapeutic effects of anti-CTLA 4 antibodies in a model of breast cancer in mice. The mechanism through which the anti-CTLA-4 antibody improves the antitumor immune response involves prompt T-cell activation and proliferation. Therefore, in order to determine whether the MMPI affected the immune microenvironment of tumor-bearing mice to enhance the therapeutic effects of the anti-CTLA-4 antibody, we used flow cytometry to measure changes in the percentages of $\mathrm{CD}^{+} \mathrm{T}$ cells, $\mathrm{CD}^{+}$ T cells, Tregs, Th17 cells, and MDSCs in the spleens of mice and to evaluate changes of MDSCs in the bone marrow. The results showed that there were no significant differences in the number of $\mathrm{CD}^{+}$and $\mathrm{CD}^{+} \mathrm{T}$ cells between the groups (Fig. 4). However, the ratio of $\mathrm{CD}^{+} \mathrm{T}$ cells to $\mathrm{CD} 4^{+} \mathrm{T}$ cells was significantly increased after MMPI treatment ( $\mathrm{P}<0.05$; Fig. 4). Moreover, combined treatment caused significant decreases in Tregs and the Treg/Th17 ratio in mouse spleens $(\mathrm{P}<0.01$; Fig. 4), and the percentage of MDSCs in spleens and the bone marrow was significantly reduced after combination treatment $(\mathrm{P}<0.01$; Fig. 4).

Thus, taken together, these data suggested that the anticancer mechanism of the MMPI may be related to the increased proportion of $\mathrm{CD}^{+} \mathrm{T}$ cells, relieving immune suppression and enhancing the antitumor function of the immune system.

Treatment with the MMPI and anti-CTLA-4 antibody improves the TME. The primary target of MMPIs is the TME, which is generally enriched in immunosuppressive cells. Thus, we examined the infiltration of immune cells into tumor tissues using immunofluorescence. The results showed that while there were no obvious increases in the percentage of $\mathrm{CD}^{+}$and $\mathrm{CD}^{+} \mathrm{T}$ cells in the TME, the ratio of $\mathrm{CD}^{+} \mathrm{T}$ cells to $\mathrm{CD} 4^{+} \mathrm{T}$ cells was increased after MMPI treatment and after combined treatment as compared with that in vehicle-treated mice $(\mathrm{P}<0.05$; Fig. 5). Moreover, the percentages of Tregs, Th17 cells, and MDSCs in the tumors were significantly decreased after combined treatment $(\mathrm{P}<0.05$ for Tregs and Th17 and $\mathrm{P}<0.01$ for MDSCs; Fig. 5). However, the Treg/Th17 ratio did not differ significantly compared with that in vehicle-treated mice. Therefore, these data showed that immunosuppression of the TME was improved to a certain extent after combination treatment with the MMPI and anti-CTLA-4 antibody.

Combined treatment with the MMPI and anti-CTLA-4 antibody reduced the MVD within the TME. Tumor vessels are important elements of the TME, and MVD within the tumor is often associated with tumor progression. We selected paraffinembedded sections of tumors, stained them with anti-CD34 antibodies to mark tumor stromal vascular endothelial cells, and determined the MVD. Immunohistochemical staining showed that the MVD was higher in tumors from vehicletreated mice than in tumors from mice treated with the MMPI and anti-CTLA-4 antibody ( $\mathrm{P}<0.01$; Fig. 6). Thus, the MMPI may reduce immunosuppression and inhibit neovascularization in the TME.

Correlation between immune cell and MVD within the TME. Immune cells are associated with angiogenesis in the tumor 
A

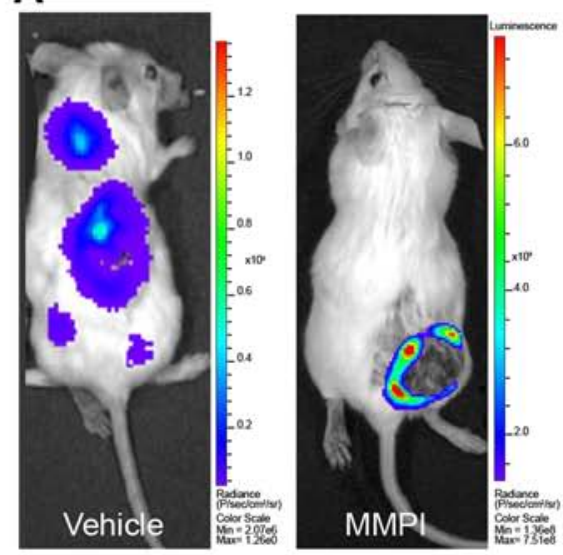

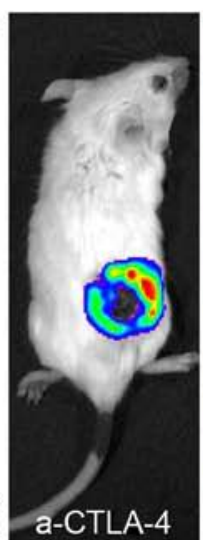

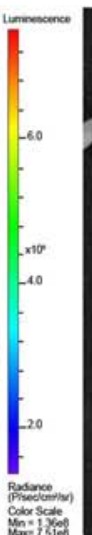

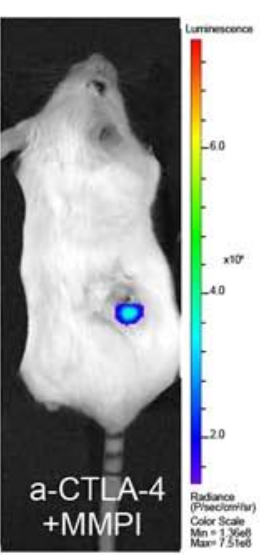

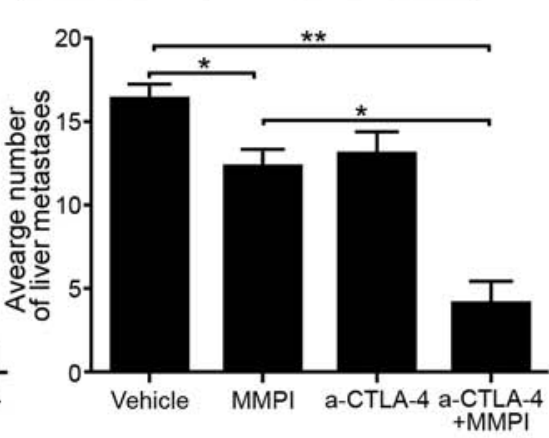

B
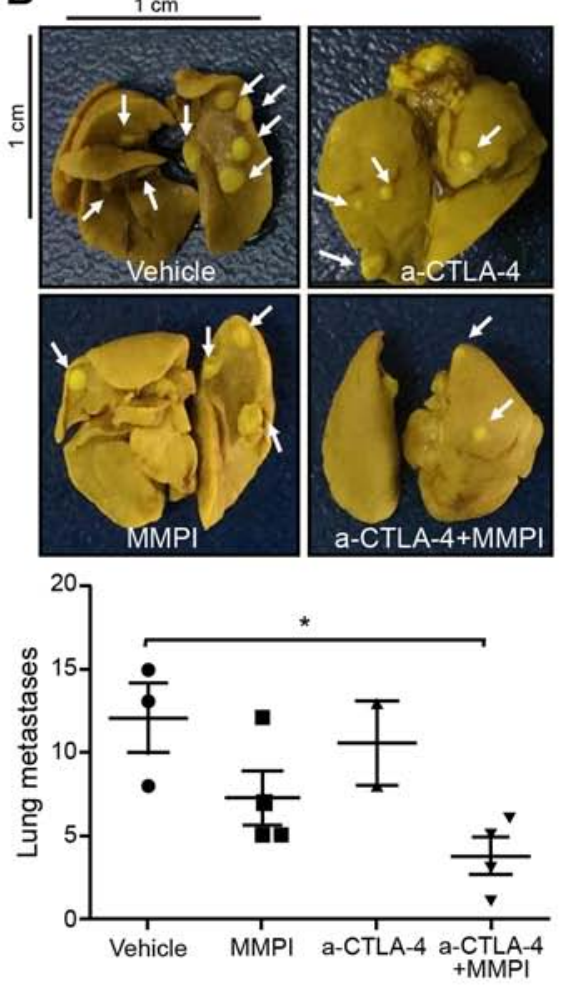

Lung
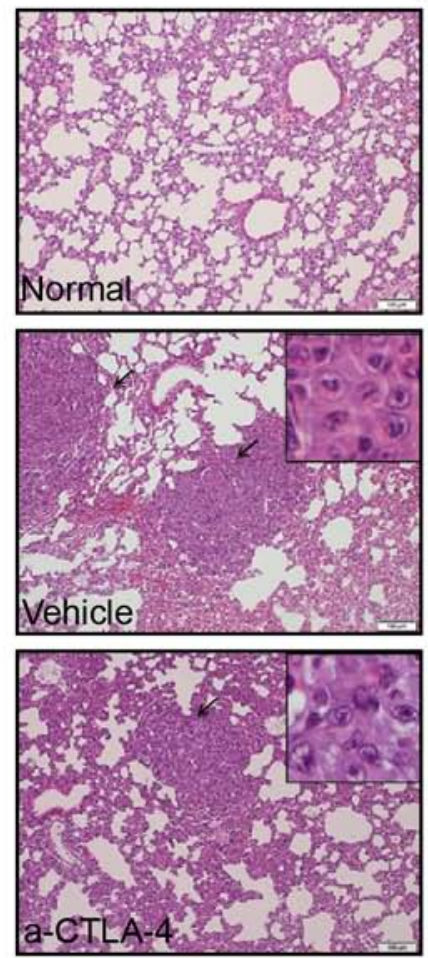
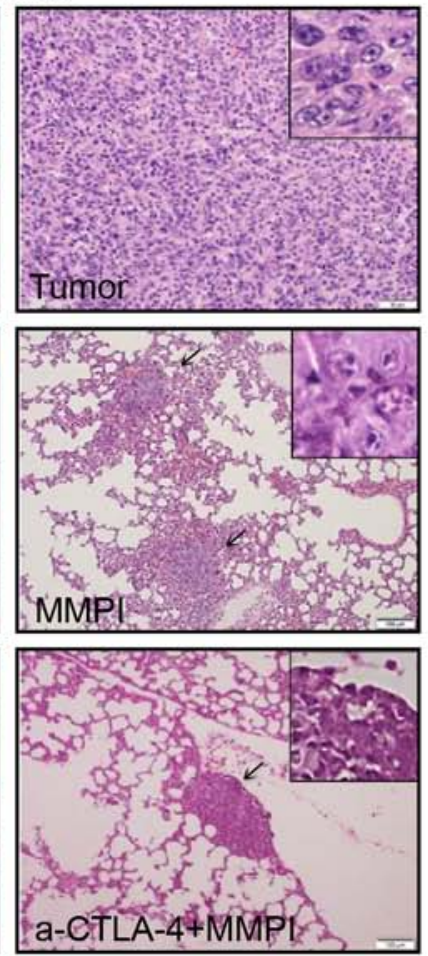

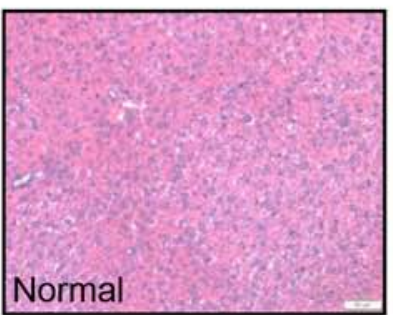

Liver

\section{Norma}

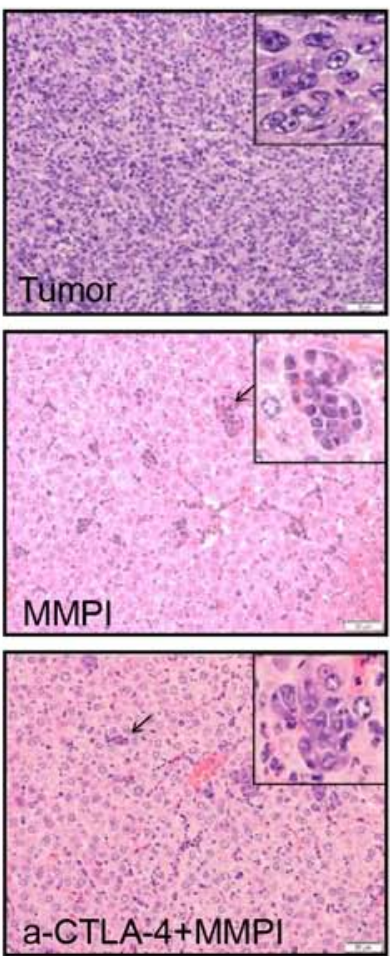

Figure 2. Effects of the MMP inhibitor and anti-CTLA-4 antibody treatment on breast cancer metastasis. (A) In vivo imaging of tumor metastases. Mice were anesthetized using $4 \%$ chloral hydrate by intraperitoneal injection. Anesthetized mice were injected intraperitoneally with $200 \mu 1$ of D-luciferin $(15 \mathrm{mg} / \mathrm{ml})$. After $10 \mathrm{~min}$, the mice were imaged using a small animal in vivo optical imaging system. (B) Detection of metastases on the surface of lungs. The lungs were immediately placed into Bouin's fixative. Metastases on the lungs were faint yellow in color, and normal lungs were dark yellow in color after $48 \mathrm{~h}$, with a clear boundary between the two tissues. The number of metastatic lesions on the pulmonary surface was counted with the naked eye $\left({ }^{*} \mathrm{P}<0.05\right.$, Student's t-test, non-parametric test). (C) Detection of metastases in the lungs and liver by H\&E staining. * $\mathrm{P}<0.05$, Student's t-tests, non-parametric tests.

stroma (12). Therefore, we next analyzed the relationship between infiltration of immune cells and MVD within the tumor tissue. Spearman correlation analyses showed that $\mathrm{CD} 8^{+}$ $\mathrm{T}$ cells, $\mathrm{CD} 4^{+} \mathrm{T}$ cells, and the $\mathrm{CD} 8^{+} / \mathrm{CD}^{+} \mathrm{T}$ cell ratio were 


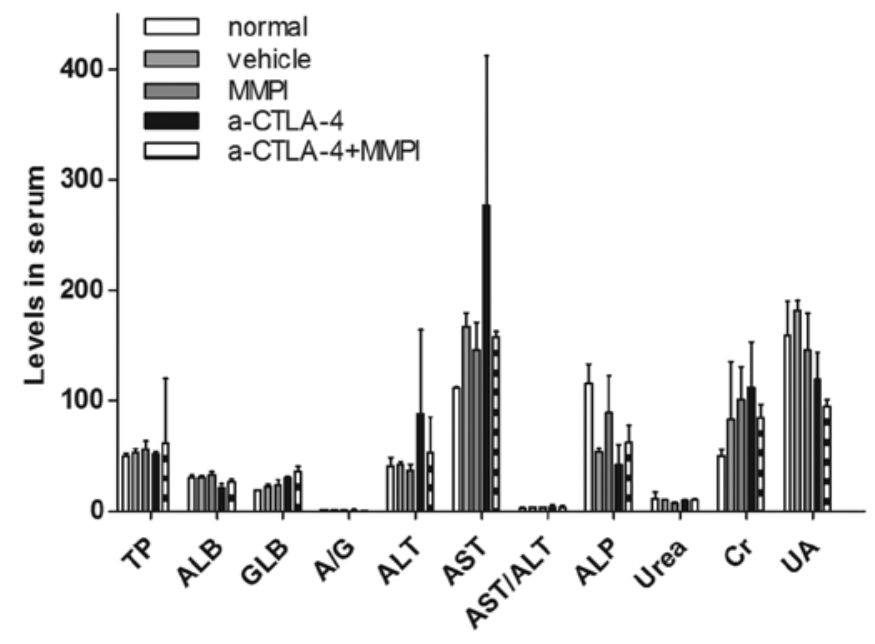

Figure 3. Functional analysis of the liver and kidneys after treatment with the MMP inhibitor and anti-CTLA-4 antibody. Blood serum was obtained from tumor-bearing mice after treatment and normal 6-8-week-old female BALB/c mice $(n=3)$. Total protein (TP, g/l), serum albumin (ALB, g/l), serum globulin (GLB, g/l), A/G, alanine aminotransferase (ALT, U/1), aspartate aminotransferase (AST, U/1), ALT/AST and alkaline phosphatase (ALP, U/1) were measured using an automatic biochemical analyzer to investigate the function of the livers. Urea $(\mathrm{mM} / 1)$, creatinine $(\mathrm{Cr}, \mu \mathrm{M} / 1)$, and uric acid (UA, $\mu \mathrm{M} / 1$ ) were measured to determine the function of the kidneys. The average of each index was determined, and the value for each treatment group was compared with that of the normal group (Student's t-test, nonparametric test).

negatively correlated with MVD in tumor tissues (correlation coefficients: $-0.800,-0.800$, and -0.100 , respectively; $\mathrm{P}>0.05$ ), whereas Tregs, the Treg/Th17 ratio, Th17 cells, and MDSCs were positively correlated with MVD (correlation coefficients: $0.400,0.400,0.800$ and 0.800$)$; the correlation between MDSCs and MVD was statistically significant $(\mathrm{P}<0.05$; Fig. 7$)$.

\section{Discussion}

In this study, we examined the therapeutic effects of combined treatment with an MMPI and anti-CTLA-4 antibody in a breast cancer model in mice. Our data demonstrated that addition of MMPI enhanced the effects of anti-CTLA-4 antibody treatment in a mouse model of breast cancer by delaying tumor growth and reducing metastases. These results may have important implications in the development of novel therapeutic strategies for the treatment of breast cancer.

Murine breast cancer 4T1 cell can spontaneously metastasize to other organs after subcutaneous injection into female BALB/c mice. This process is similar to the occurrence and development of human breast cancer; therefore, transplantation of 4T1 cells into mice is considered an ideal model for studying human breast cancer (13). The application of anti-CTLA-4 antibodies alone is ineffective for the treatment of breast cancer in mice (14). Therefore, successful immunotherapy using anti-CTLA-4 antibodies would require identification of the appropriate combination therapy. Recent studies have shown that the TME mediates immune escape and regulates the sensitivity of tumors to anticancer drugs; therefore, targeting of the TME may represent a novel method for the treatment of malignant tumors.
MMPs play an important role in tumor progression by regulating the TME. MMPs promote angiogenesis, tumor growth, and tumor spread through the degradation of extracellular matrix, thereby changing the adhesion between cells, promoting cell movement, and regulating the immune response of the tumor (15). Based on the overexpression of MMPs in tumor tissues and the overactivation of MMPs observed in tumors (16), application of an MMPI could block the activity of MMPs, improve the TME, and inhibit tumor growth (17). Indeed, many animal experiments and clinical trials have shown that MMPIs have different degrees of inhibitory effects on tumor growth but are often accompanied by obvious side effects $(18,19)$. Therefore, identification of an MMPI with low toxicity and high efficacy is necessary. In the present study, we used the MMPI potassium ferricyanide, a member of a class of inorganic compounds identified through enzyme kinetics experiments in a previous study. This compound exhibits low toxicity, has weak stimulation in the skin and eyes, and produces toxic gases only when exposed the strong acids. Potassium ferricyanide specifically inhibits MMP-14, MMP-2, and MMP-13 through non-competitive inhibition. Our results of combination therapy with the MMPI (potassium ferricyanide) and anti-CTLA-4 antibody showed that anti-CTLA-4 antibody alone exhibited poor efficacy, consistent with a study by Demaria et al (14), combined treatment with the MMPI and anti-CTLA-4 antibody significantly inhibited the growth and metastasis of breast cancer. Therefore, inhibition of MMPs may improve the therapeutic effects of the anti-CTLA-4 antibody.

Tumor cells are often able to evade immune surveillance and induction of immune tolerance and are thought to be associated with various types of immune cells, including MDSCs, Tregs, and Th17 cells (20-22). The antitumor immune response is markedly suppressed by immunosuppressive cells within the body; these cells tend to be found in tumors after treatment with an immunological stimulus, facilitating the development of a microenvironment promoting tumor immunosuppression (23). Tregs play a role in immunosuppression mainly through CTLA-4 on the cell surface (24). MDSCs can produce arginine to inhibit T-cell function and can secrete transforming growth factor (TGF)- $\beta$ and IL-10 to inhibit T-cell activation (25). Our data suggested that the percentage of Tregs and MDSCs was reduced in spleens and tumors after the combination treatment. Tregs are primarily developed from naïve $\mathrm{CD} 4^{+} \mathrm{T}$ cells, and TGF- $\beta$ is the key factor involved in Treg development; indeed, TGF- $\beta$ can induce the expression of Foxp3, a transcription factor that facilitates the transformation of naïve $\mathrm{CD}^{+} \mathrm{T}$ cells into Tregs (26). MMP-14 induces TGF- $\beta 1$ protein expression (27); therefore, MMPI may regulate the expression of TGF- $\beta$, thus reducing the number of Tregs (28). Additionally, the growth of MDSCs, a large group of naïve cells derived from the bone marrow, can be inhibited by MMP-2 through upregulation of a number of immune suppressor genes, including IL-10, IL-14, IL-11, and chemokine ligand CCL-5 (29). Because the MMPI used in our study could inhibit the activity of MMP-2, we expect that the MMPI may have inhibited the growth of MDSCs, thereby reducing MDSC numbers. Our data also suggested that MDSCs in bone marrow was declined after combined treatment. It was reported that TGF- $\beta$ signaling pathway is an important factor in regulation of bone marrow- 

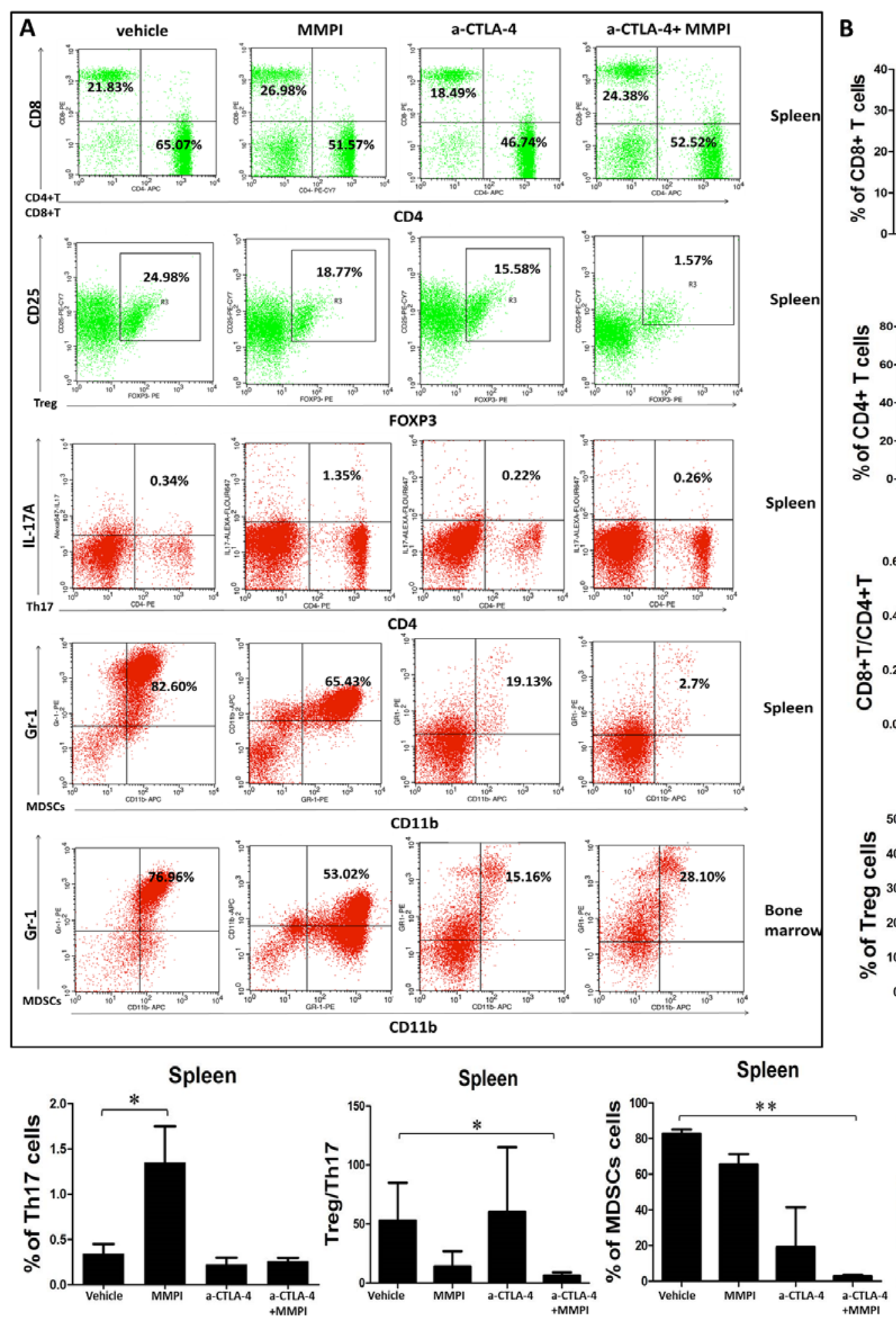
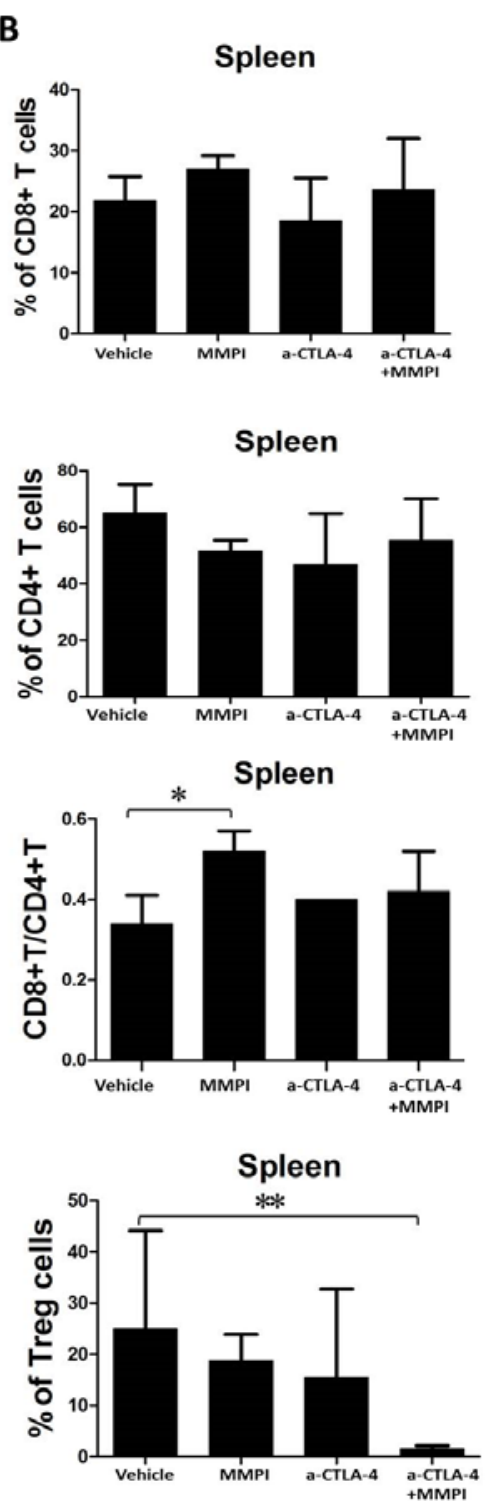

Bone marrow

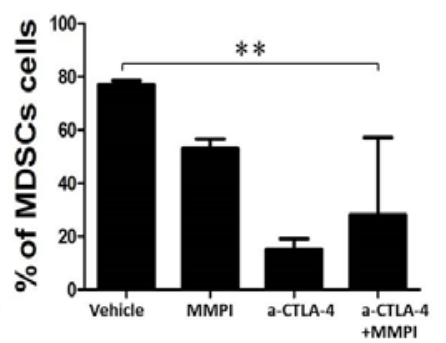

Figure 4. Analysis of immune cells in the spleen and bone marrow after treatment with the MMP inhibitor and anti-CTLA-4 antibody. (A) Immune cells obtained from spleen and bone marrow were, respectively, analyzed using flow cytometry. CD4, CD8, Treg, Th17, and MDSCs were stained with CD3/CD4, CD3/CD8, CD4/CD25/FOXP3, CD4/IL-17A, and CD11b/Gr-1. MDSCs were blocked with CD16/CD32 before staining. Statistical significance was determined using two-sample Student's t-tests. ${ }^{*} \mathrm{P}<0.05 ;{ }^{* *} \mathrm{P}<0.01 ;{ }^{* * * *} \mathrm{P}<0.001$.

derived MDSCs $(28,30)$. Thus, the inhibition of MMPs may have influence on mature MDSCs. Exosomes may be another factor by which tumor exosomes can switch the differentiation pathway of myeloid cells to the MDSC pathway and of which tumor exosomes will reduce after treatment (31).
Blood vessels in tumors are an important part of the TME and can support the growth of tumors, promote the spread of the tumor cells, and regulate the TME. The tumor vasculature is abnormal, exhibiting circuity and expansion in structure, morphological and structural abnormalities in perithelial cells 

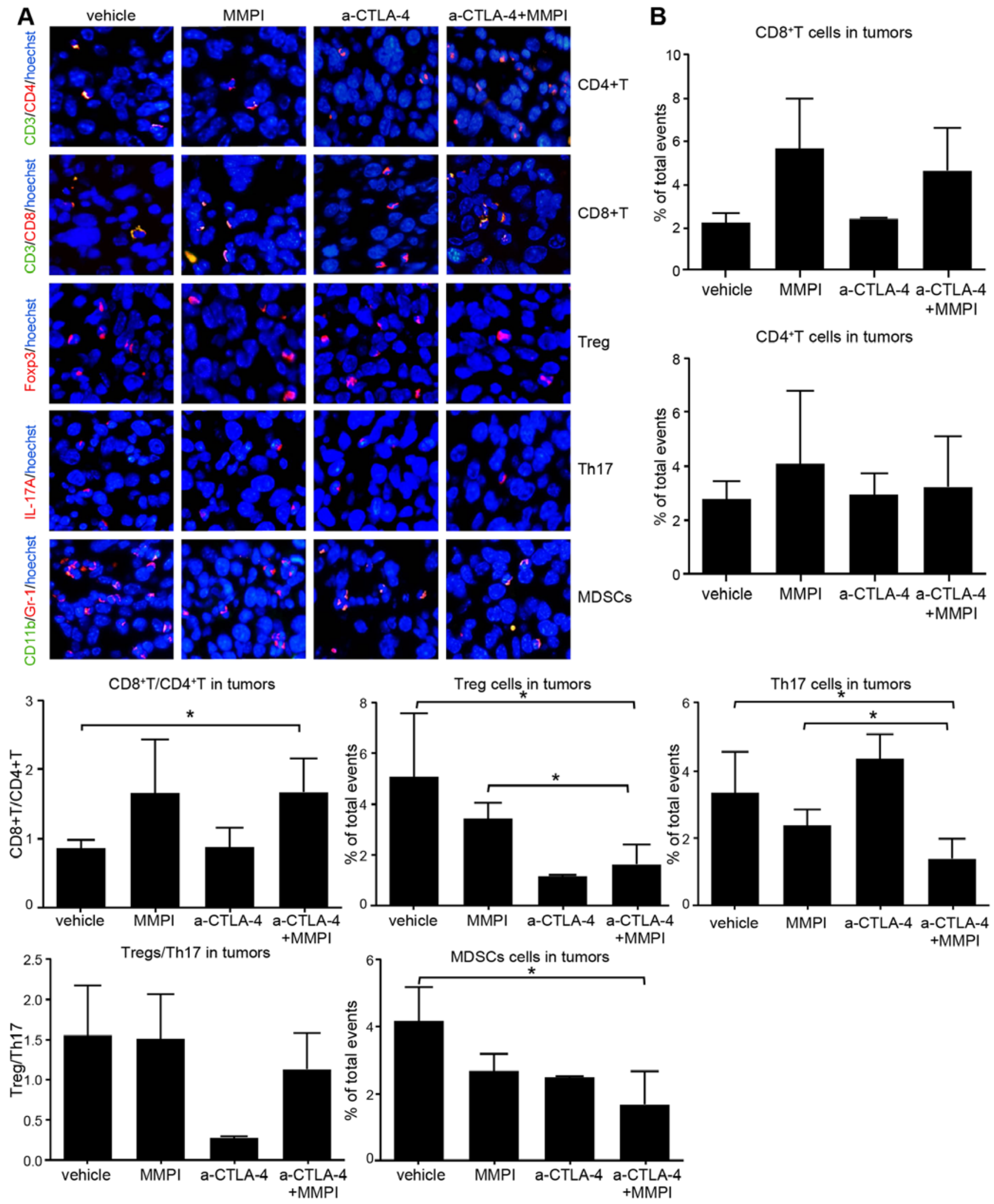

Figure 5. Effects of the MMP inhibitor and anti-CTLA-4 antibody treatment on the tumor immune microenvironment. (A) Immune cells in the tumor microenvironment were determined by immunofluorescence staining for CD3-FITC/CD4-PE/Hochest33342 (x400), CD3-FITC/CD8-PE/Hochest33342 (x400), Foxp3-PE/Hoechst-33342 (x400), IL-17A-Alexa Fluor 647/Hoechst-33342 (x400), and CD11b-FITC/Gr-1-PE/Hoechst-33342 (x400). (B) Quantitative analysis of total cell numbers was conducted using Image-Pro plus based on Hoechst-33342 staining. Statistical analysis was performed using Student's t-tests and non-parametric tests ( $\mathrm{P}<0.05)$.

that are loosely connection or even absent, an incomplete basement membrane, and increased MVD (33). The abnormal blood vessel formation can create an abnormal TME, further affecting the proliferation, invasion, survival, and function 

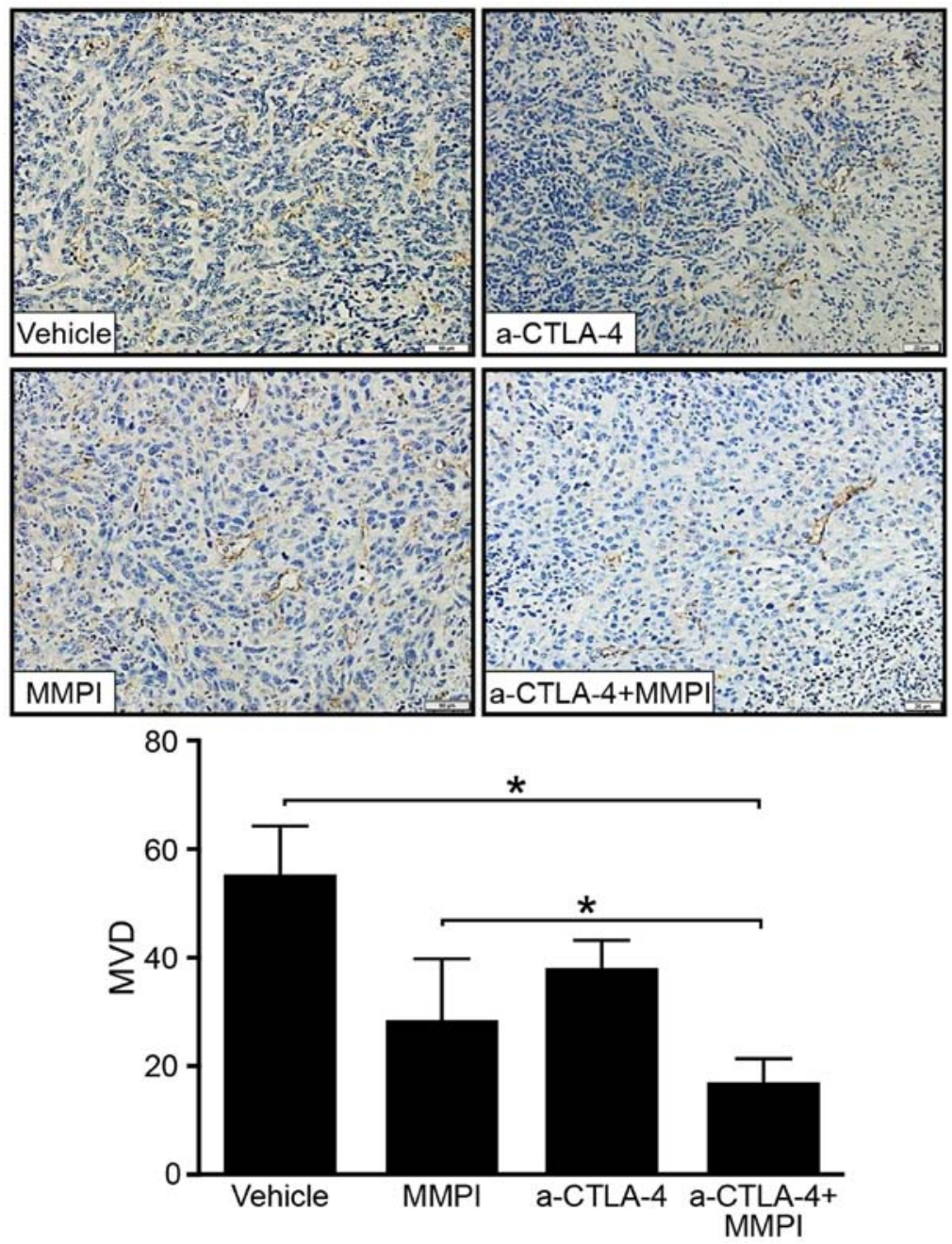

Figure 6. MMPI and a-CTLA-4 antibody treatment decreased intratumoral microvessel density. Blood vessels in tumors identified by CD34 primary monoclonal antibody (1:100) were tested by immunohistochemistry. Tumor microvascular density (MVD) is the average of microvascular number with five microscopic fields. Statistical significance was determined using the Student's t-tests and non-parametric tests. "P<0.05.

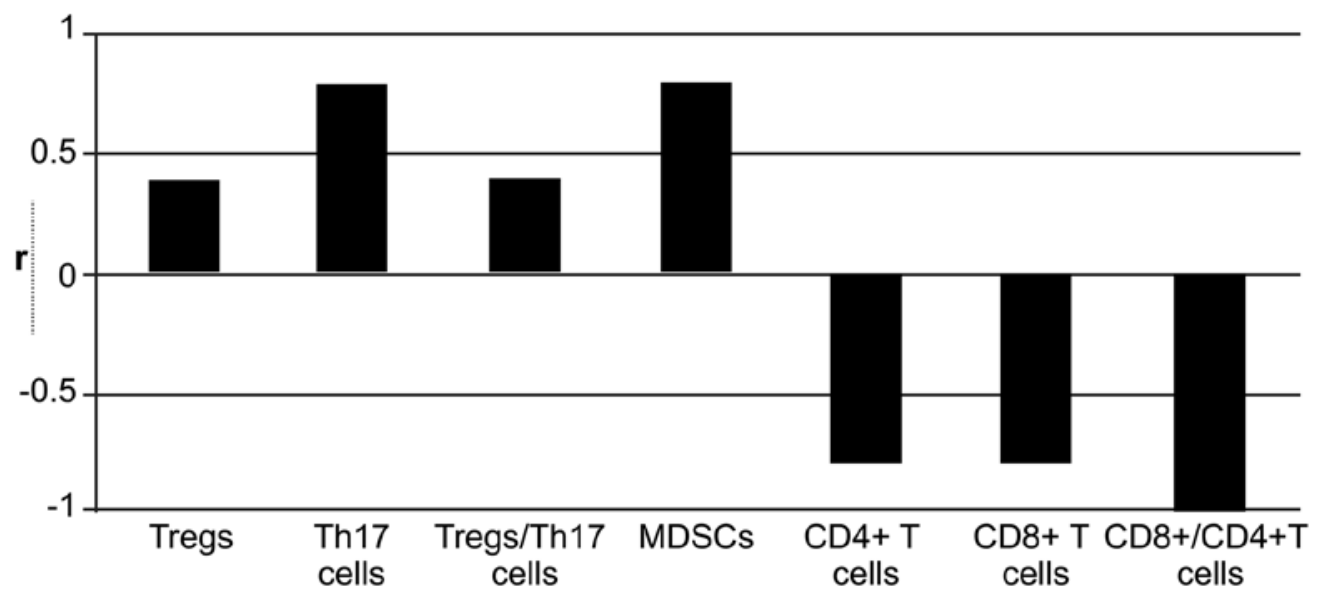

Figure 7. MMPI and a-CTLA-4 antibody treatment decreased intratumoral microvessel density. Spearman correlation analysis was used. CD8 ${ }^{+}$, CD4 $4^{+}$, and $\mathrm{CD} 8^{+} / \mathrm{CD} 4^{+} \mathrm{T}$ cells were negatively correlated with MVD. Tregs, Tregs/Th17 cells, Th17 cells, and MDSCs were positively correlated with MVD. The correlation between MDSCs and MVD was statistically significant ( $\mathrm{P}<0.05$, Student's t-tests).

of immune cells $(33,34)$. Therefore, the TME is generally characterized by a lack of antitumor immune cells and the accumulation of immunosuppressive cells. Additionally, sustained low concentrations of anti-angiogenic agents can reduce the tumor vascular density, reshape the abnormal blood vessels in the TME, balance vascular perfusion, increase the 
effects of T-cell infiltration, and improve the immunosuppressive effects of the TME $(35,36)$.

Our data showed that the anti-CTLA-4 antibody alone could not effectively reduce the MVD in tumors; however, combined treatment with the MMPI and anti-CTLA-4 antibody significantly reduced the MVD in tumor tissues. MMPs can promote angiogenesis by degrading the vascular basement membrane, thereby regulating angiogenic factors. MMP-14 plays an important role within the TME and affects angiogenesis by regulating the expression of vascular endothelial growth factor (VEGF) and the biological activities of TGF- $\beta$ (37). Therefore, the MMPI used in this study may inhibit the angiogenesis-promoting effects of MMPs, thereby reducing the MVD in the TME. In addition, immune cells, particularly immunosuppressive cells, regulate angiogenesis in the TME. Our data suggested that Tregs, Th17 cells, and MDSCs were positively correlated with MVD in the TME; these cells may promote tumor angiogenesis (12). Moreover, hypoxia can promote the infiltration of Tregs into the TME by mediating VEGF-A expression, subsequently promoting endothelial cell recruitment and amplification (38). In ovarian cancer, Tregs are an important source of VEGF in the TME, and removal of Tregs can effectively reduce the production of VEGF. Additionally, Tregs are required for angiogenesis in lung tissue (39). In an alternatively pathway, MDSCs stimulate the activation of signal transducer and activator of transcription 3 (STAT3) in tumor cells via secretion of IL-28 and induction of tumor-associated factors. The tumor cells then promote the formation of tubular structures by endothelial cells (40). Importantly, MDSCs are factors involved in mediating the effects of anti-angiogenic therapy in cancer (41). Angiogenesis is also affected by the expression of IL-17A, which is secreted by Th17 cells and is positively associated with the MVD in gastric cancer, liver cancer, and breast cancer (42). IL-17A indirectly participates in angiogenesis by promoting the secretion of VEGF, prostaglandin E2 (PGE2), and chemotactic factors from tumor cells. IL-17A can also directly affect endothelial cells and endothelial progenitor cells to promote angiogenesis (43). Therefore, the observed reduction in Tregs, Th17 cells, and MDSCs in response to the MMPI in our study may explain the reduction in the MVD. Reducing the MVD through application of the MMPI could also further inhibit immune cell infiltration.

In a recent study in mice, inhibition of MMP-14 improved tumor blood perfusion and oxygen supply by increasing the expression of inducible nitric oxide synthase (iNOS) and heatshock protein 90 (HSP90) and also resulted in bending of the blood vessels within the tumor (44). Vascular remodeling can improve the abnormal state of tumor blood vessels, enhance vascular perfusion, and increase drug delivery. In addition to MMP-14, MMP-2 plays an important role in promoting tumor vascular remodeling (45). Moreover, MMPI has been shown to enhance the therapeutic effects of chemotherapy drugs on tumors by promoting remodeling of the tumor vasculature and increasing drug delivery (46). Thus, the MMPI we used may promote tumor vascular remodeling to a certain extent.

$\mathrm{CD} 4^{+}$and $\mathrm{CD} 8^{+} \mathrm{T}$ cells are the main effector cells of antitumor immune responses and can combine with tumor associated antigens, MHC-I and MHC-II molecules to induce tumor cells death through secretion of cytokines and other cytotoxic effects. Thus, the number of $\mathrm{CD}^{+}$and $\mathrm{CD} 8^{+} \mathrm{T}$ cells can reflect the antitumor immunity of tumor-bearing mice. Unexpectedly, we did not see an increase in the number of $\mathrm{CD} 4^{+}$and $\mathrm{CD}^{+} \mathrm{T}$ cells after treatment. However, the ratio of $\mathrm{CD}^{+} \mathrm{T}$ cells to $\mathrm{CD} 4^{+} \mathrm{T}$ cells $\left(\mathrm{CD} 8^{+} / \mathrm{CD} 4^{+} \mathrm{T}\right.$ cells) was increased in tumor after combined treatment and in spleen after MMPI treatment. The different cell sources may be the cause for the different results. The characteristics of $4 \mathrm{~T} 1$ cells themselves and the reduction in Tregs, a type of $\mathrm{CD}^{+} \mathrm{T}$ cell, may explain this unexpected result.

In conclusion, our data showed that the MMPI used in this study inhibited angiogenesis in the TME and suppressed the infiltration of immunosuppressive cells. Therefore, the MMPI may regulate blood vessels and immunosuppressive cells, together or separately, within the TME, thereby making the TME less favorable for tumor growth and enhancing the anticancer effects of anti-CTLA-4 antibody. Notably, tumor neovascularization and tumor infiltrating immune cells are two main components in TME. The main target of CTLA-4 antibody and MMPI is the immune cells and blood vessels, respectively. Thus, we only examined the two main factors most relevant to tumor progression in the TME. There may be other factors related to these processes that have not yet been identified. Further studies are needed to determine the functions of immunosuppressive cells regulating blood vessels in the TME.

\section{Acknowledgements}

We thank Professor Xuexun Fang (Key Laboratory for Molecular Enzymology and Engineering of Ministry of Education, Jilin University, China) for providing the MMPI potassium ferricyanide $\left\{\mathrm{K}_{3}\left[\mathrm{Fe}(\mathrm{CN})_{6}\right]\right\}$. This study was supported by the Jilin Provincial Science and Technology Projects (grant no. 20130102084JC) and the Frontier Interdisciplinary Program of Norman Bethune Health Science Center of Jilin University (grant no. 2013101005).

\section{References}

1. Lotem M, Merims S, Frank S, Ospovat I and Peretz T: Ctla-4 blockade: A new hope for the immunotherapy of malignant melanoma. Harefuah 151: 585-588, 604, 2012 (In Hebrew).

2. Prieto PA, Yang JC, Sherry RM, Hughes MS, Kammula US, White DE, Levy CL, Rosenberg SA and Phan GQ: CTLA-4 blockade with ipilimumab: Long-term follow-up of 177 patients with metastatic melanoma. Clin Cancer Res 18: 2039-2047, 2012.

3. McAllister SS and Weinberg RA: The tumour-induced systemic environment as a critical regulator of cancer progression and metastasis. Nat Cell Biol 16: 717-727, 2014.

4. Baginska J, Viry E, Paggetti J, Medves S, Berchem G, Moussay E and Janji B: The critical role of the tumor microenvironment in shaping natural killer cell-mediated anti-tumor immunity. Front Immunol 4: 490, 2013

5. Whiteside TL: Induced regulatory T cells in inhibitory microenvironments created by cancer. Expert Opin Biol Ther 14: 1411-1425, 2014.

6. Borriello L and DeClerck YA: Tumor microenvironment and therapeutic resistance process. Med Sci (Paris) 30: 445-451, 2014 (In French).

7. Hida K, Akiyama K, Ohga N, Maishi N and Hida Y: Tumour endothelial cells acquire drug resistance in a tumour microenvironment. J Biochem 153: 243-249, 2013.

8. Kessenbrock K, Plaks V and Werb Z: Matrix metalloproteinases: Regulators of the tumor microenvironment. Cell 141: 52-67, 2010 . 
9. Shuman Moss LA, Jensen-Taubman S and Stetler-Stevenson WG: Matrix metalloproteinases: Changing roles in tumor progression and metastasis. Am J Pathol 181: 1895-1899, 2012.

10. Thomas D, Ritz MF, Malviya AN and Gaillard S: Intracellular acidification mediates the proliferative response of PC12 cells induced by potassium ferricyanide and involves MAP kinase activation. Int J Cancer 68: 547-552, 1996.

11. Martinus RD, Linnane AW and Nagley P: Growth of rho 0 human Namalwa cells lacking oxidative phosphorylation can be sustained by redox compounds potassium ferricyanide or coenzyme Q10 putatively acting through the plasma membrane oxidase. Biochem Mol Biol Int 31: 997-1005, 1993.

12. Stockmann C, Schadendorf D, Klose R and Helfrich I: The impact of the immune system on tumor: Angiogenesis and vascular remodeling. Front Oncol 4: 69, 2014.

13. Tao K, Fang M, Alroy J and Sahagian GG: Imagable 4T1 model for the study of late stage breast cancer. BMC Cancer 8: 228, 2008.

14. Demaria S, Kawashima N, Yang AM, Devitt ML, Babb JS, Allison JP and Formenti SC: Immune-mediated inhibition of metastases after treatment with local radiation and CTLA-4 blockade in a mouse model of breast cancer. Clin Cancer Res 11: 728-734, 2005.

15. Fink $\mathrm{K}$ and Boratyński J: The role of metalloproteinases in modification of extracellular matrix in invasive tumor growth, metastasis and angiogenesis. Postepy Hig Med Dosw Online 66: 609-628, 2012 (In Polish).

16. Benson CS, Babu SD, Radhakrishna S, Selvamurugan N and Ravi Sankar B: Expression of matrix metalloproteinases in human breast cancer tissues. Dis Markers 34: 395-405, 2013.

17. Overall CM and Kleifeld O: Tumour microenvironment opinion: Validating matrix metalloproteinases as drug targets and anti-targets for cancer therapy. Nat Rev Cancer 6: 227-239, 2006.

18. Li NG, Tang YP, Duan JA and Shi ZH: Matrix metalloproteinase inhibitors: A patent review (2011-2013). Expert Opin Ther Pat 24 1039-1052, 2014.

19. Li W, Saji S, Sato F, Noda M and Toi M: Potential clinical applications of matrix metalloproteinase inhibitors and their future prospects. Int J Biol Markers 28: 117-130, 2013.

20. Srivastava MK, Zhu L, Harris-White M, Huang M, St John M, Lee JM, Salgia R, Cameron RB, Strieter R, Dubinett S, et al: Targeting myeloid-derived suppressor cells augments antitumor activity against lung cancer. Immunotargets Ther 2012: 7-12, 2012.

21. Radosavljević GD, Jovanović IP, Kanjevac TV and Arsenijević NN: The role of regulatory T cells in the modulation of anti-tumor immune response]. Srp Arh Celok Lek 141: 262-267, 2013 (In Serbian)

22. Prabhala RH, Pelluru D, Fulciniti M, Prabhala HK, Nanjappa P, Song W, Pai C, Amin S, Tai YT, Richardson PG, et al: Elevated IL-17 produced by TH17 cells promotes myeloma cell growth and inhibits immune function in multiple myeloma. Blood 115 5385-5392, 2010

23. Becker JC, Andersen MH, Schrama D and Thor Straten P. Immune-suppressive properties of the tumor microenvironment. Cancer Immunol Immunother 62: 1137-1148, 2013.

24. Walker LS: Treg and CTLA-4: Two intertwining pathways to immune tolerance. J Autoimmun 45: 49-57, 2013.

25. Nagaraj S, Youn JI and Gabrilovich DI: Reciprocal relationship between myeloid-derived suppressor cells and T cells. J Immunol 191: 17-23, 2013

26. Li Z, Li D, Tsun A and Li B: FOXP3 ${ }^{+}$regulatory T cells and their functional regulation. Cell Mol Immunol 12: 558-565, 2015.

27. Kumar S, Pan CC, Bloodworth JC, Nixon AB, Theuer C, Hoyt DG and Lee NY: Antibody-directed coupling of endoglin and MMP-14 is a key mechanism for endoglin shedding and deregulation of TGF- $\beta$ signaling. Oncogene 33: 3970-3979, 2014.

28. Krstic J and Santibanez JF: Transforming growth factor-beta and matrix metalloproteinases: Functional interactions in tumor stroma-infiltrating myeloid cells. Sci World J 2014: 521754, 2014
29. Guedez L, Jensen-Taubman S, Bourboulia D, Kwityn CJ, Wei B, Caterina J and Stetler-Stevenson WG: TIMP-2 targets tumor-associated myeloid suppressor cells with effects in cancer immune dysfunction and angiogenesis. J Immunother 35: $502-512,2012$.

30. Fan Q, Gu D, Liu H, Yang L, Zhang X, Yoder MC, Kaplan MH and Xie J: Defective TGF- $\beta$ signaling in bone marrow-derived cells prevents hedgehog-induced skin tumors. Cancer Res 74: 471-483, 2014

31. Xiang X, Poliakov A, Liu C, Liu Y, Deng ZB, Wang J, Cheng Z, Shah SV, Wang GJ, Zhang L, et al: Induction of myeloid-derived suppressor cells by tumor exosomes. Int J Cancer 124: 2621-2633, 2009.

32. Hida K, Kawamoto T, Ohga N, Akiyama K, Hida Y and Shindoh M: Altered angiogenesis in the tumor microenvironment. Pathol Int 61: 630-637, 2011.

33. Goubran HA, Kotb RR, Stakiw J, Emara ME and Burnouf T: Regulation of tumor growth and metastasis: The role of tumor microenvironment. Cancer Growth Metastasis 7: 9-18, 2014.

34. Mittal K, Ebos J and Rini B: Angiogenesis and the tumor microenvironment: Vascular endothelial growth factor and beyond. Semin Oncol 41: 235-251, 2014.

35. Chauhan VP, Stylianopoulos T, Martin JD, Popović Z, Chen O, Kamoun WS, Bawendi MG, Fukumura D and Jain RK: Normalization of tumour blood vessels improves the delivery of nanomedicines in a size-dependent manner. Nat Nanotechnol 7: 383-388, 2012

36. Trédan O, Lacroix-Triki M, Guiu S, Mouret-Reynier MA, Barrière $\mathrm{J}$, Bidard $\mathrm{FC}$, Braccini $\mathrm{AL}$, Mir $\mathrm{O}$, Villanueva $\mathrm{C}$ and Barthélémy P: Angiogenesis and tumor microenvironment: Bevacizumab in the breast cancer model. Target Oncol 10: 189-198, 2015.

37. Sounni NE, Paye A, Host L and Noël A: MT-MMPS as regulators of vessel stability associated with angiogenesis. Front Pharmacol 2: 111, 2011.

38. Pucino V, De Rosa V, Procaccini C and Matarese G: Regulatory $\mathrm{T}$ cells, leptin and angiogenesis. Chem Immunol Allergy 99: 155-169, 2014.

39. D'Alessio FR, Zhong Q, Jenkins J, Moldobaeva A and Wagner EM: Lung angiogenesis requires CD4 (+) forkhead homeobox protein-3 (+) regulatory T cells. Am J Respir Cell Mol Biol 52: 603-610, 2015.

40. Mucha J, Majchrzak K, Taciak B, Hellmén E and Król M: MDSCs mediate angiogenesis and predispose canine mammary tumor cells for metastasis via IL-28/IL-28RA (IFN- $\lambda$ ) signaling. PLoS One 9: e103249, 2014.

41. Finke J, Ko J, Rini B, Rayman P, Ireland J and Cohen P: MDSC as a mechanism of tumor escape from sunitinib mediated antiangiogenic therapy. Int Immunopharmacol 11: 856-861, 2011.

42. Yang B, Kang H, Fung A, Zhao H, Wang T and Ma D: The role of interleukin 17 in tumour proliferation, angiogenesis, and metastasis. Mediators Inflamm 2014: 623759, 2014.

43. Numasaki M, Fukushi J, Ono M, Narula SK, Zavodny PJ, Kudo T, Robbins PD, Tahara H and Lotze MT: Interleukin-17 promotes angiogenesis and tumor growth. Blood 101: 2620-2627, 2003.

44. Ager EI, Kozin SV, Kirkpatrick ND, Seano G, Kodack DP, Askoxylakis V, Huang Y, Goel S, Snuderl M, Muzikansky A, et al: Blockade of MMP14 activity in murine breast carcinomas: Implications for macrophages, vessels, and radiotherapy. J Natl Cancer Inst 107: 107, 2015.

45. Romanchikova N, Trapencieris P, Zemītis J and Turks M: A novel matrix metalloproteinase-2 inhibitor triazolylmethyl aziridine reduces melanoma cell invasion, angiogenesis and targets ERK1/2 phosphorylation. J Enzyme Inhib Med Chem 29: 765-772, 2014.

46. Weisshardt P, Trarbach T, Dürig J, Paul A, Reis H, Tilki D, Miroschnik I, Ergün S and Klein D: Tumor vessel stabilization and remodeling by anti-angiogenic therapy with bevacizumab. Histochem Cell Biol 137: 391-401, 2012. 